ÁREA TEMÁTICA: ÁREAS DEGRADADAS E CONTAMINADAS.

\title{
ESTUDO PRELIMINAR DOS IMPACTOS SOCIOAMBIENTAIS NA COMUNIDADE PARQUE VITÓRIA, AO ENTORNO DA MICROBACIA DO IGARAPÉ MATA FOME, PRATINHA II, NO MUNICÍPIO DE BELÉM/PA.
}

\section{Rosa Helena Ribeiro Cruz - cruzrh@gmail.com}

Universidade do Estado do Pará

Fábio Sérgio Lima Brito - fabio.lima.ufpa@gmail.com

Universidade Federal do Pará

Karla Karoline Leite do Rosário - karlaleite93@ gmail.com

Universidade do Estado do Pará

Mateus Souza Morais - mateussmorais8@gmail.com

Universidade Federal do Pará

Wilian Victor da Silva Campos - wiliancampos17@ hotmail.com

Universidade do Estado do Pará 


\section{RESUMO}

O trabalho consiste em um estudo preliminar dos impactos socioambientais da comunidade Parque Vitória, Pratinha II, em torno da Bacia Hidrográfica do Igarapé Mata Fome (BHIMF) no bairro do Tapanã, Belém - PA. Como objetivos específicos: avaliar a geração de lixo ao entorno do igarapé, identificar o assoreamento do igarapé, avaliar a falta de saneamento básico na comunidade. Para este estudo foi selecionada a região da bacia hidrográfica do Mata Fome, localizado no parque vitória, Pratinha II pois vem sofrendo uma grande transformação desde a década de 80 após a região em seu entorno ter sido ocupada de forma desordenada por dezenas de famílias vindas de outras áreas de Belém. A área de estudo será na Pratinha II, mais precisamente nas comunidades parque vitória e Parque Verde, bairro do Tapanã, dados estes do período de agosto e outubro 2015. A metodologia a ser aplicada será a observativa participativa, onde o pesquisador analisa a realidade social que o rodeia. Como resultados esperados deste estudo acredita-se que podemos contribuir para o despertar das comunidades para as principais formas de transformações socioambientais em suas áreas, alavancando assim com a melhoria da vida urbana em suas comunidades.

Palavras-chave: Mata Fome, Impactos Socioambientais, Saneamento.

\section{INTRODUÇÃO/OBJETIVO}

No início do século XX quando o Brasil começou seu processo de industrialização houve um grande aumento da migração de pessoas vindas de áreas rurais para os centros urbanos que se formavam. O que é conhecido como êxodo rural fazendo com que o país mudasse seu modelo agrário-exportador para urbano industrial (DIEESE, 2012).

Atualmente, mais de 160 milhões de pessoas, cerca de $84 \%$ da população brasileira, vive em áreas urbanas (IBGE, 2010). Mas, como é possível observar, na maioria das cidades brasileiras existem grandes desigualdades sociais por conta do processo de urbanização das cidades ter ocorrido sem muito planejamento gerando grandes problemas sociais.

De acordo com Brito e Pinho (2012), o processo de urbanização no Brasil é um dos determinantes estruturais da constituição da sociedade moderna brasileira. 


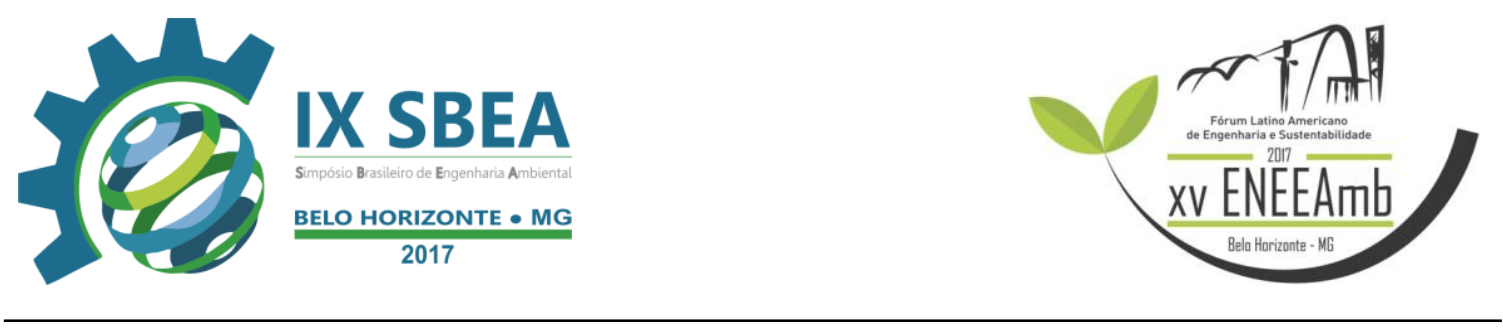

Articulado a um conjunto de transformações sociais, econômicas e demográficas pelas quais o País tem passado, principalmente, a partir da segunda metade do século XX.

Quando falamos em urbanização não devemos ter em mente algo que foi vivido e que hoje teve seu fim considerando apenas o processo atual das cidades no mundo todo, e sim um processo que está em constante mudança. É possível observar isso em diversas cidades brasileiras ao se verificar periodicamente sua mudança estrutural.

Segundo Santos (2005), o maior salto populacional urbano deu-se entre 1940 e 1980. Houve uma troca de moradias da população, onde a taxa de urbanização em 1940 era de 26,35\% e em 1980 alcançou 68,86\%. No CENSO 2010 (IBGE, 2010) comparando a população que vive na área rural e na área urbana, as mudanças acentuaram-se contemplando $15,63 \%$ da população brasileira morando na área rural e $84,36 \%$ em área urbana.

Esses dados mostram o grande crescimento que as cidades passam e como essas mudanças trazem grandes desafios para quem as governa. Trata-se de uma ocupação intensa e sobretudo desordenada.

Nepomuceno Sobrinho (2009) afirma que um dos principais sinais de degradação do meio ambiente urbano é identificado nos locais de deposição dos resíduos sólidos e suas consequências para a saúde da população que trabalha e mora em seu entorno.

Assim, tomando-se como referência o fato de a maior parte da população brasileira viver em cidades, observa-se uma crescente degradação das condições de vida, refletindo uma crise ambiental. Isto remete a uma necessária reflexão sobre os desafios para mudar as formas de pensar e agir em torno da questão ambiental numa perspectiva contemporânea (JACOBI, 2003).

O objetivo do estudo foi realizar um estudo preliminar dos impactos socioambientais da comunidade Parque Vitória, Pratinha II, em torno da bacia hidrográfica do Mata Fome no bairro do Tapanã, Belém - PA.

Como objetivos específicos: identificar os principais problemas socioambientais na comunidade, avaliar a geração de lixo ao entorno do igarapé, identificar o assoreamento do igarapé, avaliar a falta de saneamento básico na comunidade.

\section{METODOLOGIA}




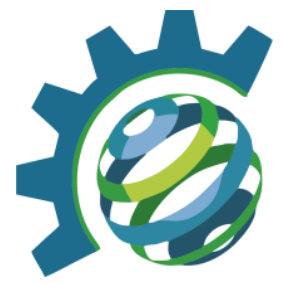

\section{Área de estudo}

O estudo foi realizado no bairro Pratinha II (Figura 01), mas precisamente na Bacia Hidrográfica do Igarapé Mata Fome, localizada na comunidade parque vitória, bairro do Tapanã, a bacia está compreendida entre as coordenadas geográficas

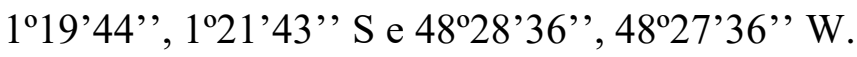

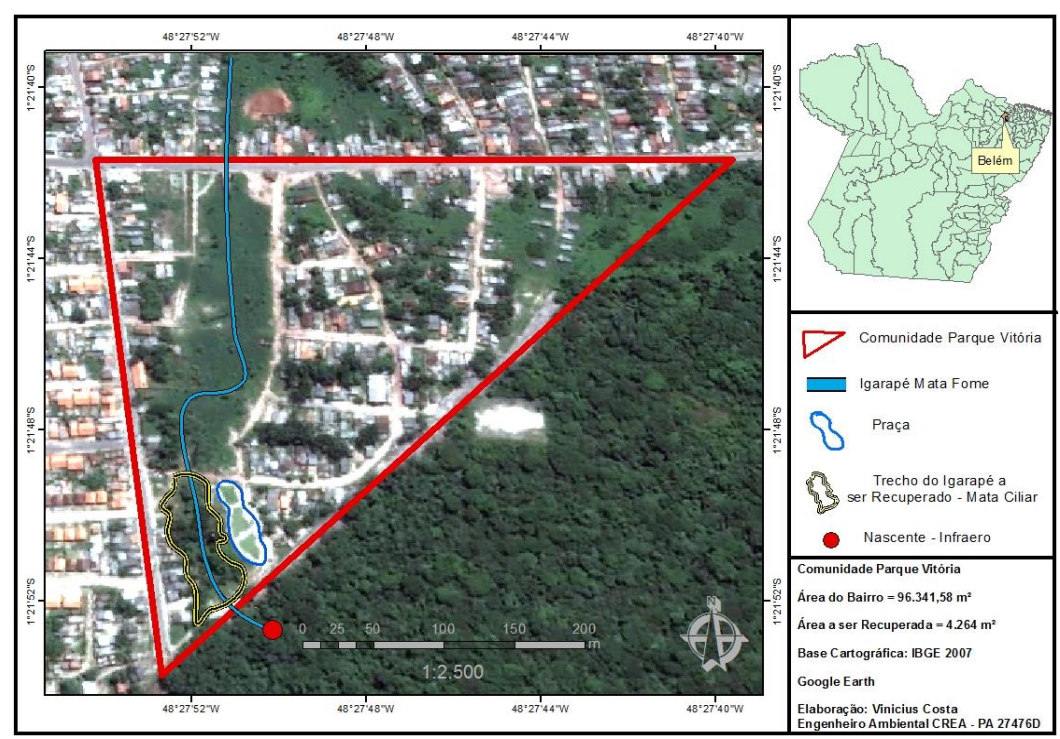

Figura 01: Mapa de localização igarapé Mata Fome

Fonte: Costa, 2014

\section{Pesquisa de Campo}

Foi aplicada a metodologia observativa participativa onde o pesquisador analisa a realidade social que o rodeia. Para identificar os impactos socioambientais foram utilizados mecanismos estruturados para coletar, analisar, comparar e organizar informações e dados sobre impactos.

Foram realizadas algumas visitas na área para conhecimento dos problemas mencionados; participação em reuniões com lideranças comunitárias, para avaliação dos estudos; participação em palestras montadas para a área da bacia.

\section{RESULTADOS E DISCUSSÕES}

A invasão do entorno do Igarapé Mata Fome ocorreu devido ao crescimento acelerado e sem planejamento do centro da cidade de Belém. Ribeiro e Prost (2000) e Prost (2000) consideram a invasão recente, de aproximadamente 15 anos. 


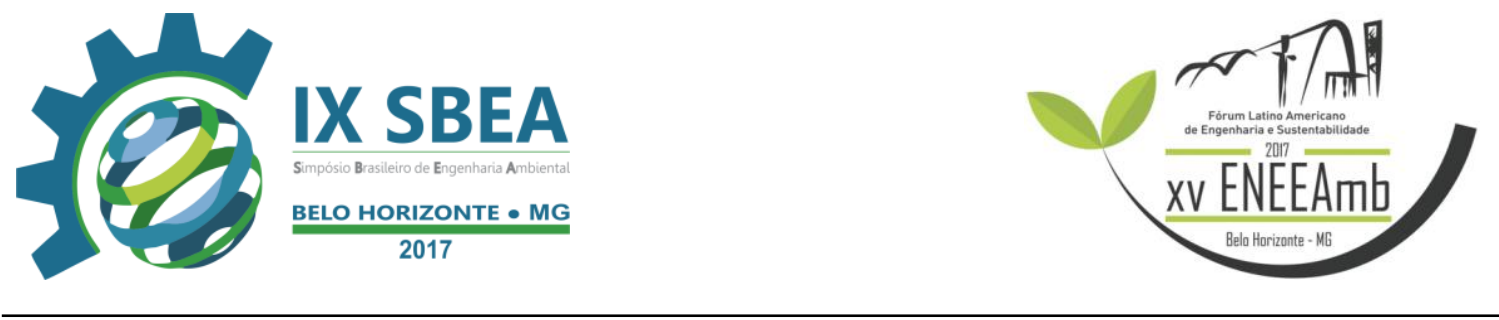

A Comunidade do entorno do Igarapé Mata Fome é um exemplo da realidade que vem acontecendo em todas as típicas cidades latino-americanas de grande porte, sendo caracterizada por intensas desigualdades intraurbana (Figura 02), bem como o caráter concentrador do processo de urbanização.

No entanto, ao serem questionados sobre suas memórias e sobre o sentimento de pertença, os moradores do entorno do Igarapé Mata Fome apenas evidenciam a casa em que vivem, pois os mesmos não viveram na comunidade uma evolução no que diz respeito a melhorias dos serviços urbanos. Para os mesmos, a relação de sentimento só é existente com a própria casa, já que, como relatado pelos mesmos, é a única coisa que possuem.

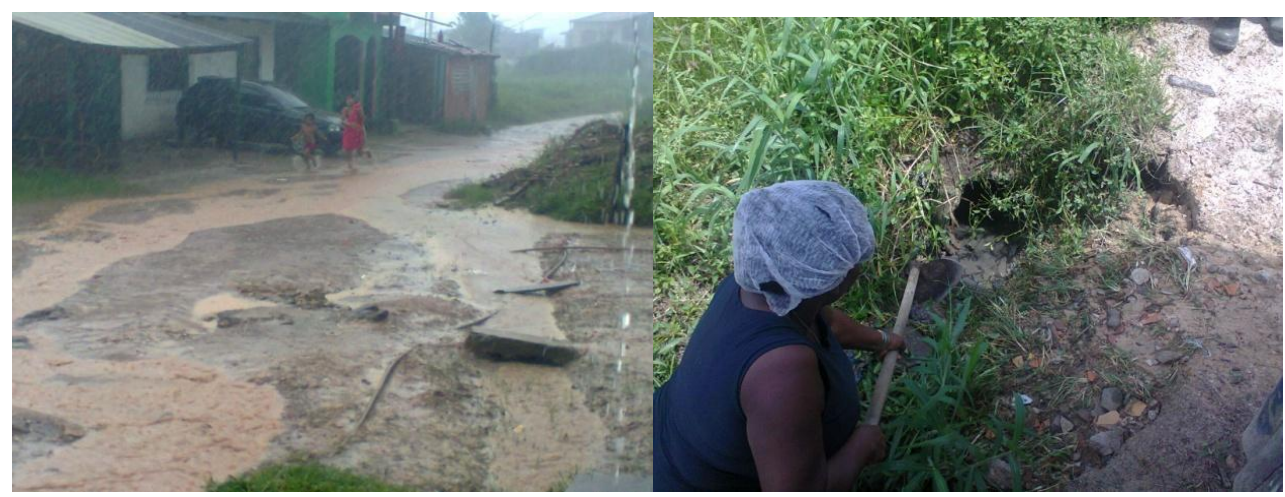

Figura 02: Impactos urbanos no parque Vitória

Fonte: Viana, 2015.

Que de acordo com a caracterização socioambiental da BHIMF apresentado por Leite et.al.2007, podemos afirmar que a região da BHIMF é caracterizada pela presença de diversas fontes de contaminação das águas, tais como, postos de combustíveis, despejo de esgoto, oficinas de automóveis, são lançados no esgoto pluvial. Podemos destacar ainda.

Condições sanitárias precárias onde, segundo Craveiro (2007), existe carência da rede de esgoto doméstico que atenda a população, causando o despejo de detritos humanos diretamente no solo, escoando para o igarapé, o que constitui risco de contaminação das águas superficiais e, podendo inclusive contaminar as águas subterrâneas que interagem com elas;

Os poços existentes na área da BHIMF constituem importantes focos potenciais de contaminação, pois são construídos sem nenhuma técnica ou preocupação 


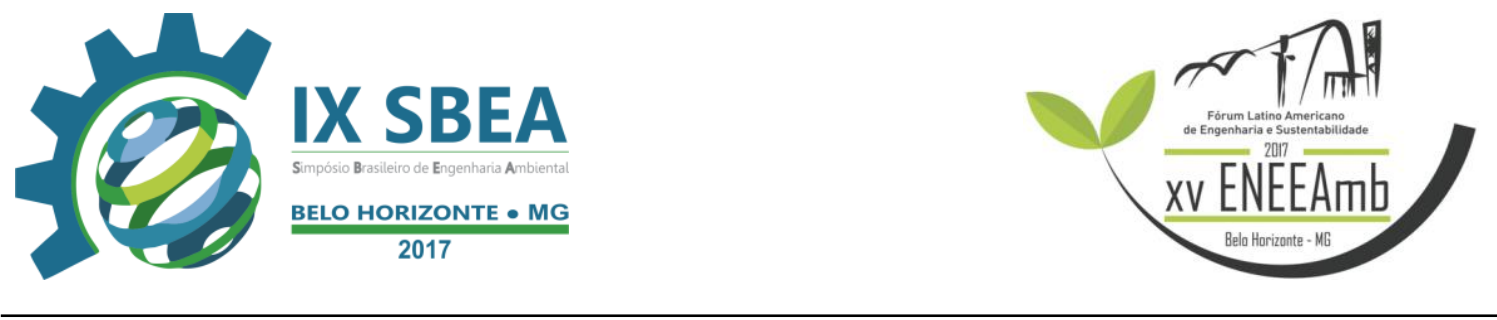

com higiene geralmente com rasas profundidades, constituindo importante vetores de doenças.

O assoreamento (Figura 03) do Igarapé Mata Fome é reforçado pelo lançamento de lixo e esgoto em seu leito, "a matéria orgânica produzida pelos moradores da Bacia é lançada diretamente no Igarapé. Os banheiros, por exemplo, são construídos sobre pontes de madeira feitas com a vegetação da área, em cima do Igarapé".
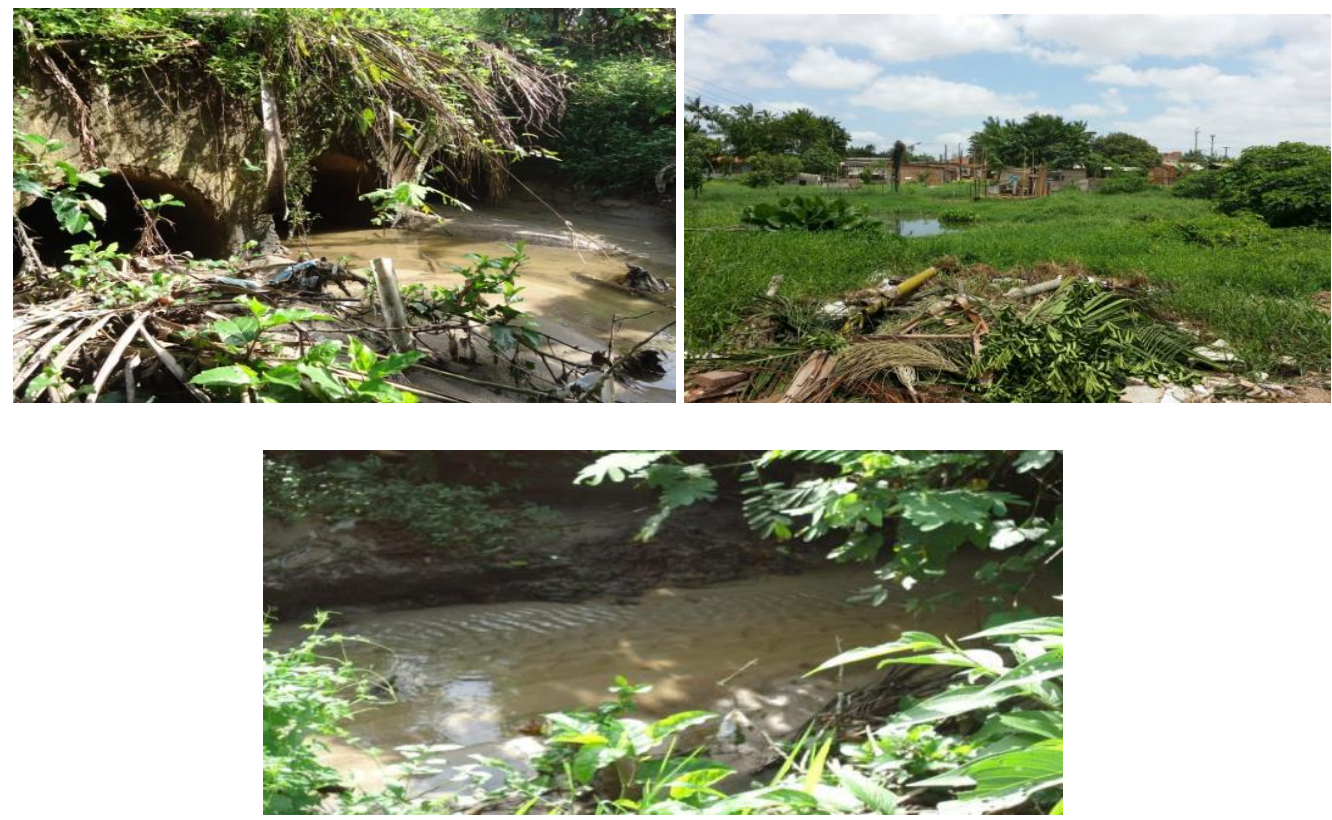

Figura 03: Assoreamento do Igarapé Mata Fome.

Fonte: Viana,2015

Outro impacto ambiental observado é a coleta de lixo seletiva, que no início do processo de invasão não era realizada e, atualmente, é realizada três vezes por semana. Relata, porém, um morador da área que muitos moradores não contribuem para a limpeza da comunidade (Figura 04), o que prejudica a saúde dos indivíduos que vivem nessas condições. 

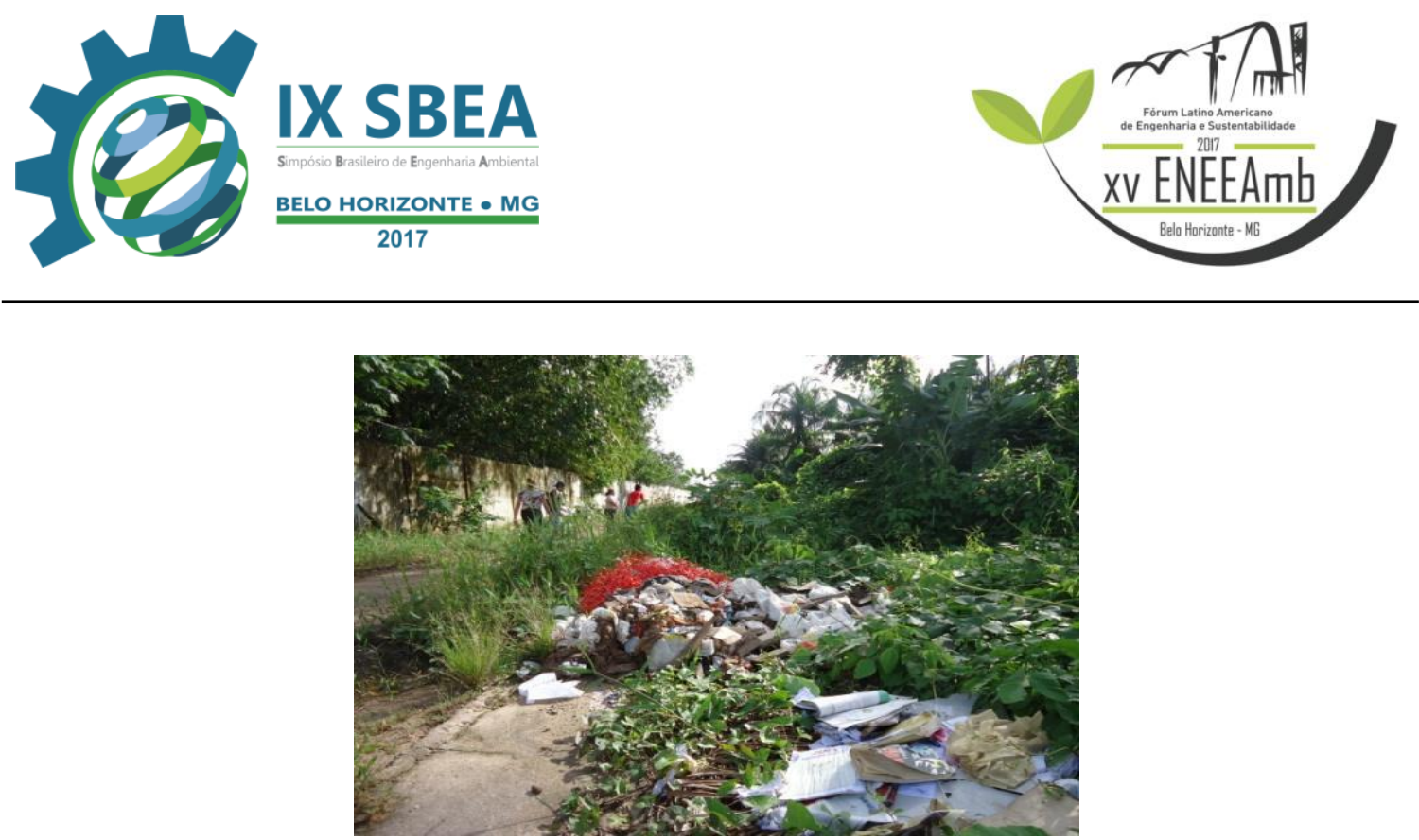

Figura 04: Lixo ao entorno do Igarapé Mata Fome

Fonte: Viana, 2015.

As instalações de esgotos não são suficientes para atender à metade da comunidade, de uma forma geral a água utilizada pelas residências é lançada diretamente no solo ou no igarapé, consequentemente esta água infiltra-se no solo, atinge o lençol freático comprovando a falta de politicas governamentais $\mathrm{e}$ caracterizando a pobreza nessas áreas. (Figura 05). Muitos moradores cavam poços rasos ou cacimbas sem nenhuma técnica para evitar contaminação por bactérias do solo, que são impróprias para o uso.

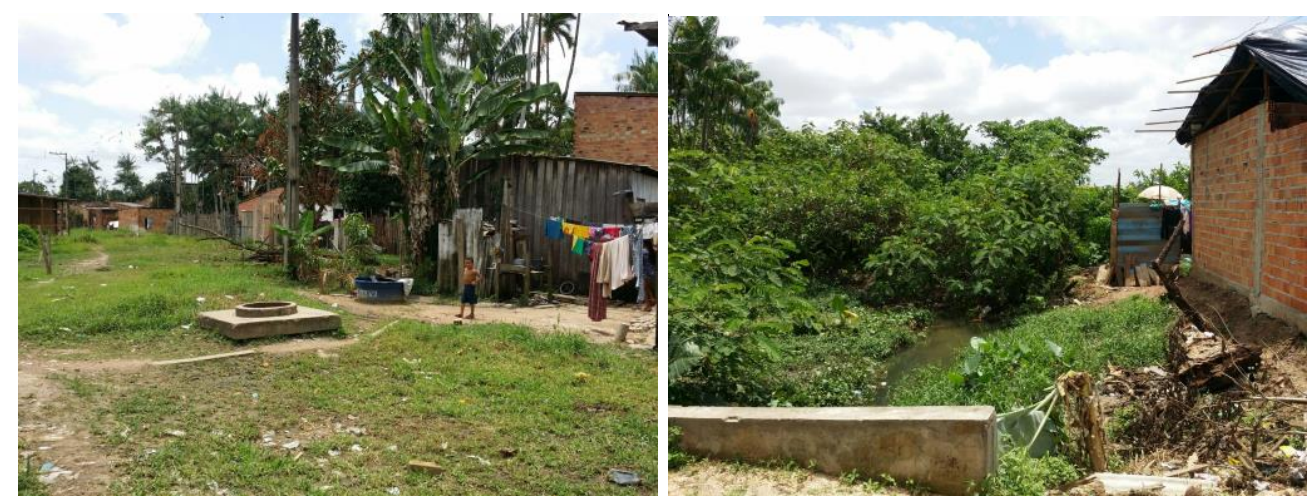

Figura 05: Poço raso e banheiros expostos.

Fonte: Viana, 2015

Na comunidade Parque Vitória existem moradores que para sua sobrevivência são catadores de lixo (Figura 06), e hoje fazem a seleção do mesmo e com isso produzem produtos artesanais, como cestas, vasos, flores e isso se transforma em renda para a família. 

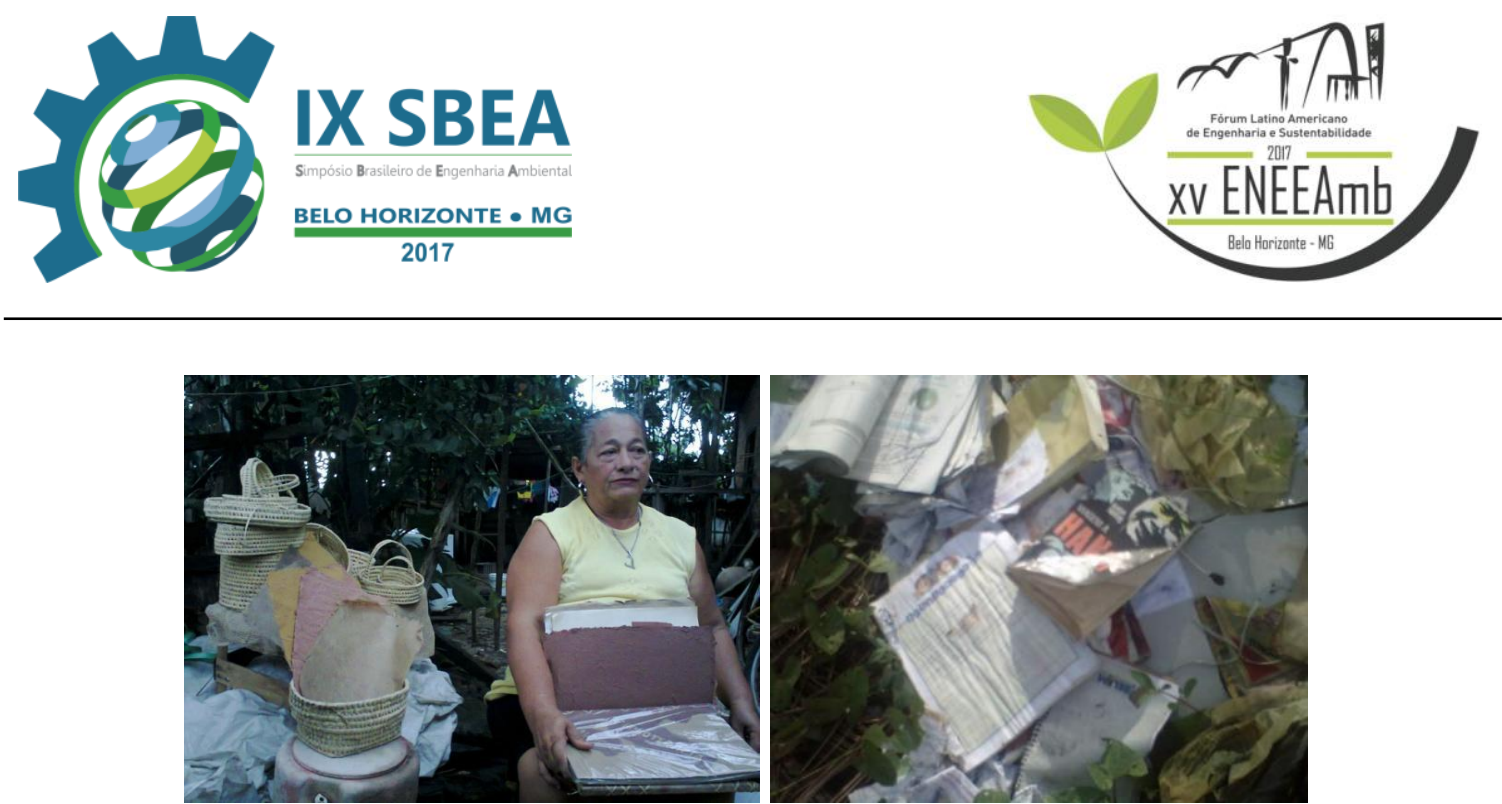

Fig.06: Catadora de lixo.

Fonte: Viana, 2015

\section{CONCLUSÕES/RECOMENDAÇÕES}

A falta de consciencia ambiental, é um problema apresentado ao entorno do igarapé Mata Fome, o que nos faz observar a falta alternativas que nos fazem despertar a consciência ambiental da vida quotidiana e com isso vamos conservar nossos recursos naturais sem polui-los.

A Falta de abastecimento público de água é insuficiente para satisfazer as necessidades locais de todos os moradores da região, presente somente para uma minoria da população, proporcionou a difusão de um conjunto significativo de poços escavados, do tipo "amazonas", por toda a área estudada, em muitos casos, gerando comercialização com sobre taxa por parte de alguns dos beneficiados, ocasionando conflitos sociais entre as comunidades.

Ausência total de politicas públicas que possa conduzir o processo de conscientização da população.

Estas conclusões têm como propósito informar à sociedade e ao poder público e político, os problemas relacionados com os aspectos sociais, culturais, ambientais e de saúde em que a população paraense está inserida, bem como permitem afirmar a importância de se perfilar políticas públicas como estratégias de novos modelos de desenvolvimento do Estado do Pará. 


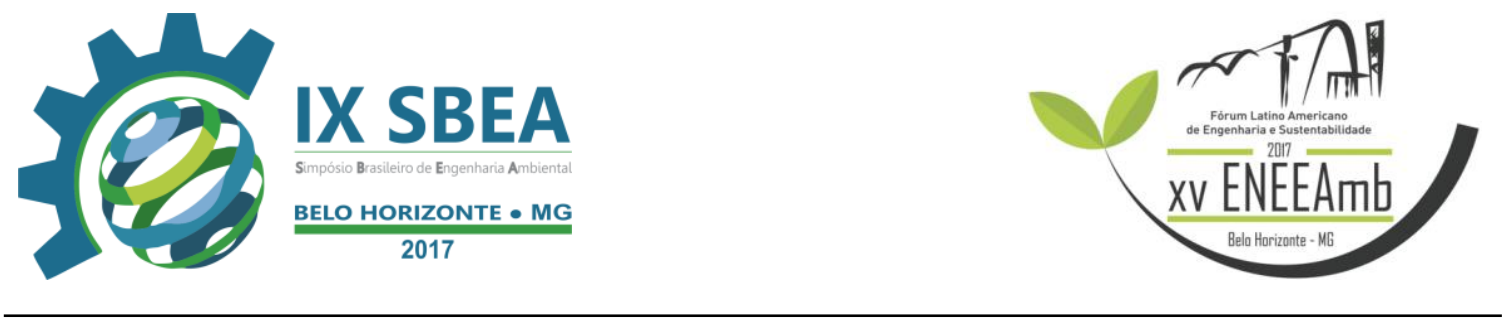

\section{RECOMENDAÇÕES}

Promover cursos de aproveitamentos de resíduos sólidos coletados em áreas tais como: reciclagem de papel, garrafas de plástico reciclagem, tratamento seletiva de lixo. Assim, incentivando a conservação das áreas ao redor do Igarapé Mata Fome e das matas ciliares regenerando ao entorno às suas raízes e assim garantir a recuperação da vegetação natural.

Formar o comitê ambiental na comunidade Parque Vitoria.

Formação de cooperativa para geração renda a partir do reaproveitamento dos Resíduos Sólidos.

Atividades de Educação ambiental para a comunidade, visualizando a preservação do meio ambiente.

Elaboração por parte dos poderes públicos projetos para a coleta de lixo nas localidades que não são beneficiadas por esse serviço, implantando uma coleta seletiva no município, com campanha para incentivar a pratica de reciclagem, além da implantação do aterro sanitário para o destino final do lixo municipal.

\section{REFERÊNCIAS BIBLIOGRÁFICAS}

BRITO, F.; PINHO, B. A. T. D. A dinâmica do processo de urbanização no Brasil, 1940-2010. In: ENCONTRO NACIONAL DE ESTUDOS POPULACIONAIS, 13., 2012, Águas de Lindóia, São Paulo.

CRAVEIRO. G. S. Um Sistema de Informação geográfica (SIG) como instrumento de gestão dos recursos Hídricos da Bacia do Mata fome - PA. Belém. 2007.

Universidade Federal do Pará. Centro de Geociências, 124p. Trabalho de Conclusão decurso - TCC. (Graduação em Geologia). 2007. GASPAR, M. T. P, Avaliação dos Impactos da Ocupação sobre as Águas da Bacia Hidrográfica do Igarapé Mata Fome. 2001. Belém, PARÁ, CPGG, Centro de Geociências, UFPA. 112p. (Dissertação de Mestrado).

DIEESE - Departamento Intersindical de Estatística e Estudos Socioeconômicos. A situação do trabalho no Brasil na primeira década dos anos 2000. São Paulo: Dieese, 2012.

GUERRA, G. A. D.; CASTRO, E. M. R.; PROST, C.. Cidadania e Meio Ambiente: considerações sobre o exercício da cidadania e os problemas sócio ambientais do Igarapé Mata Fome em Belém, Pará.. Monografia - Universidade Federal do Pará, 2000. 


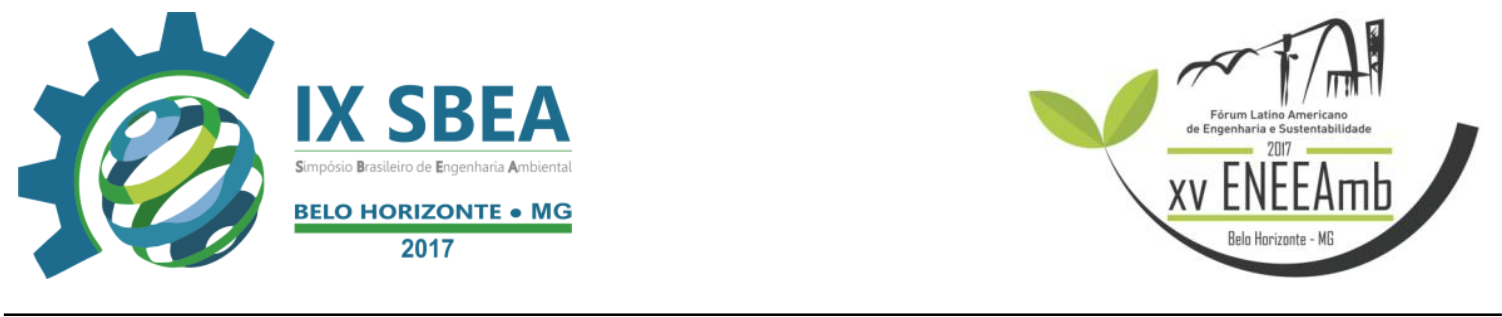

IBGE - Instituto Brasileiro de Geografia e Estatística. Censo Demográfico 2010. Rio de Janeiro: IBGE, 2010.

JACOBI, P. Educação ambiental, cidadania e sustentabilidade. Cadernos de Pesquisa, Maranhão, n. 118, p. 189-205, mar. 2003.

SANTOS, M. A urbanização brasileira. 5. ed. São Paulo: Editora da Universidade de São Paulo, 2005.

SOBRINHO, N. A reciclagem de resíduos sólidos e a questão tributária no Distrito Federal. 2009, 222 p. Dissertação de mestrado. Centro de Desenvolvimento Sustentável, Universidade de Brasília, Brasília. 